\title{
Los proyectos de Juan Bautista Lázaro para el palacio de los Guzmanes ${ }^{1}$
}

\author{
Jorge DIEZ GARCÍA-OLALLA
}

Recibido: 30-4-2013 / Aceptado: 27-6-2013

RESUMEN: El palacio de los Guzmanes fue comprado en 1882 a los Condes de Peñaranda de Bracamonte por la Diputación Provincial de León para ubicar en él sus principales dependencias. Tras hacerse con la posesión del edificio y ocupar las diferentes estancias se acordó llevar a cabo el acondicionamiento del palacio. Éste fue iniciado por el arquitecto Juan Bautista Lázaro, quien dirigiría las obras de consolidación del edificio y la recuperación de los elementos arquitectónicos originales de carácter artístico desde posturas conservadoras.

Palabras clave: Juan Bautista Lázaro, restauración patrimonial, León, palacio de los Guzmanes

ABSTRACT: Guzmanes' Palace was purchased from the Counts of "Peñaranda de Bracamonte” in 1882 by the Provincial Government of Leon to locate its main offices in it. After taking possession of the building and occupy different rooms, it was agreed to carry out the refurbishment of the palace. This was started by the architect Juan Bautista Lazaro, who would lead the consolidation of the building and the recovery of the original architectural elements which had artistic qualities using conservation principles.

Key words: Juan Bautista Lazaro, heritage restoration, Leon, Guzmanes' palace

El presente estudio pretende exponer la que debió de ser la primera obra integral de restauración que efectuó Juan Bautista Lázaro en la ciudad de León: la reparación y terminación del palacio de los Guzmanes para la Diputación Provincial de

\footnotetext{
${ }^{1}$ Este trabajo surge fruto del estudio que estoy llevando a cabo sobre las restauraciones que efectuó Juan Bautista Lázaro de Diego en la catedral leonesa de 1892 a 1909, bajo la dirección del Catedrático de Universidad Javier García-Gutiérrez Mosteiro, y que desarrollo dentro del programa de Doctorado "Conservación y Restauración del Patrimonio Arquitectónico" que se imparte en la Escuela Técnica Superior de Arquitectura de Madrid.
}

León [Fig. 1]. ${ }^{2}$ Los proyectos propuestos por Lázaro para el palacio de los Guzmanes no han sido estudiados en profundidad por los investigadores que han abordado de forma genérica la figura de este arquitecto; de todos ellos, sólo en el estudio de Javier García-Gutiérrez Mosteiro sobre la obra arquitectónica de Lázaro se menciona que dicho arquitecto había realizado la decoración neogótica del

\footnotetext{
2 Quiero agradecer al Jefe de Servicio de Archivo e Imprenta de la Diputación de León Wenceslao Álvarez Oblanca y al personal de dicho archivo la atención y ayuda prestada para la consulta del material necesario para este trabajo de investigación.
} 
salón de plenos de la Diputación. ${ }^{3}$ Por otra parte, respecto a los estudios existentes sobre el palacio, ${ }^{4}$ ninguno de ellos aborda en profundidad las obras de restauración acometidas por el arquitecto leonés Juan Bautista Lázaro en este edificio; únicamente, Wenceslao Álvarez Oblanca, en la guía que publicó sobre este monumento, ${ }^{5}$ menciona alguna de las principales actuaciones del citado arquitecto en el palacio, y $\mathrm{M}^{\mathrm{a}}$ Dolores Campos Sánchez-Bordona, en un artículo que publicó en esta misma revista varios años antes, ${ }^{6}$ cita que se le encomendó las obras de reforma de este edificio a Lázaro, exponiendo los criterios que este arquitecto aplicó en sus intervenciones de restauración en edificios de carácter monumental.

3 J. GARCÍA-GUTIÉRREZ MOSTEIRO, "La obra arquitectónica de Juan Bautista Lázaro", Academia, no 74, 1992, pp. 445-498.

${ }^{4}$ Sobre el palacio de los Guzmanes véase: J. E. DÍAZJIMÉNEZ Y MOLLEDA, La casa de los Guzmanes, León, 1906; M. BRAVO GUARIDA, "El mejor palacio leonés" en M. BRAVO GUARIDA, Rincones leoneses, León, 1935, pp. 42-44; J. RIVERA BLANCO, La arquitectura de la segunda mitad del siglo XVI en la ciudad de León, León, 1982, pp. 173-188; J. HOAG, Rodrigo Gil de Hontañón. Gótico y renacimiento en la arquitectura española del siglo XVI, Madrid, 1985; A. CASASECA CASASECA, Rodrigo Gil de Hontañón. (Rascafría 1500 - Segovia 1577), Valladolid, 1988; F. CARANTOÑA ÁLVAREZ, y G. PUENTE FELIZ (dir.), Historia de la Diputación de León, León, 1995; M. D. CAMPOS SÁNCHEZ-BORDONA, "León” en J. URREA (dir.), Casas y palacios de Castilla y León, Valladolid, 2002, pp. 92-96; y E. MORÁIS VALLEJO y M. D. CAMPOS SÁNCHEZ-BORDONA, Arquitectura y Patrimonio. Edificios civiles de la ciudad de León en la edad moderna, León, 2007, pp. 168-203.

${ }^{5}$ W. ÁLVAREZ OBLANCA, palacio de los Guzmanes. Guía, León, 1995, p. 39.

6 M. D. CAMPOS SÁNCHEZ-BORDONA, "Las transformaciones de la arquitectura señorial del renacimiento español, como reflejo del devenir histórico y del debate de las teorías restauradoras. El ejemplo del palacio de los Guzmanes de León", De Arte, no 6, 2007, pp. 167-194.

\section{LA ADQUISICIÓN DEL PALACIO Y LOS PRIMEROS PASOS PARA SU RES- TAURACIÓN}

El palacio de los Guzmanes fue comprado directamente por la Diputación Provincial a los Condes de Peñaranda de Bracamonte para instalar en él sus principales dependencias; $^{7}$ fue el 27 de mayo de 1882 cuando se formalizó la escritura de venta. ${ }^{8}$ En aquellos años el palacio estaba en buen estado de conservación aunque era necesario adaptarlo y acondicionarlo a las necesidades de la Diputación para su utilización, ${ }^{9}$ pero antes tenía que regularizarse su situación lega ${ }^{10}$ y hacerse con la posesión del

\footnotetext{
${ }^{7}$ El interés por ubicar las instalaciones de la Diputación de León en el palacio de los Guzmanes, según se recoge en la página 159 del primer volumen de la publicación Historia de la Diputación de León dirigida por Francisco Carantoña Álvarez y Gustavo Puente Feliz, se remonta a 1878, comenzándose las negociaciones para su adquisición en 1880 .

${ }^{8}$ Antes de oficiar la compra, la Diputación encargó al arquitecto Arsenio Alonso Ibáñez la elaboración del plano del edificio y de un informe para que detallara el estado real de la fábrica y determinara las posibilidades de intervención en el monumento para adecuarlo a oficinas; informe que fue presentado ante la institución provincial el 11 de junio de 1881. Se recomienda consultar para ampliar conocimientos sobre el mencionado informe: M. D. CAMPOS SÁNCHEZ-BORDONA, "Las transformaciones de la arquitectura señorial...", pp. 181-182; y "En la casa de la provincia - El palacio de los Guzmanes", Tierras de León, nº extra, enero 1978, pp. 47-55.

${ }^{9}$ Esta era al menos la opinión del arquitecto Arsenio Alonso Ibáñez y así es como lo reflejó en el informe mencionado en la nota anterior. En esta misma línea, Lázaro afirmaba en los artículos que publicó sobre la Diputación de León en la revista Anales de la Construcción y de la Industria que el edificio presentaba admirable solidez a pesar de las distintas mutilaciones que había sufrido, encontrándose su interior bastante maltratado, no sólo por el tiempo, sino también por las disparatadas reparaciones que en él se habían hecho. Véase al respecto: J. B. LÁZARO DE DIEGO, "Diputación de León", Anales de la Construcción y de la Industria, no 17, septiembre 1884, p. 260; y no 24, diciembre 1884, p. 376.

${ }^{10}$ Antes de registrar la propiedad, se tuvo que solucionar la titularidad de una fragua que se encontraba dentro del solar del palacio, según se manifiesta en: $W$. ÁLVAREZ OBLANCA, op. cit., pp. 36-37.
} 
edificio dado que, por aquel entonces, en él se encontraba la sede del Gobierno de la provincia (Gobierno Civil) y otras oficinas del Estado, como la Delegación de Hacienda, la sección de Fomento y el almacén de efectos estancados. Por todas estas circunstancias, la Diputación no lograría celebrar su primera sesión en la casa de los Guzmanes hasta el 13 de mayo de 1884.

A los pocos días de haber formalizado la compra, la Corporación tomó la decisión de iniciar las labores de mantenimiento del edificio que podía llevar a cabo mientras esperaba a que los diferentes organismos dependientes del Estado desalojaran el inmueble. Consta, según expone Wenceslao Álvarez en su guía sobre el palacio, ${ }^{11}$ que se procedió a retejar todas las cubiertas del monumento y a revisar el estado de las estufas y sus correspondientes chimeneas que existían en las diferentes dependencias, al objeto de evitar riesgos de incendio.

En los primeros meses después de haber adquirido el edificio, se pensó en llevar a cabo un plan de actuación en todo el conjunto, aprobándose el 17 de junio de 1883, a propuesta del diputado José María Lázaro, la convocatoria de un concurso para restaurar completamente el palacio, "quitando de él adosamientos que le afean", y cuyas propuestas de intervención serían remitidas a la Academia de Bellas Artes al tratarse de un edificio de interés histórico artístico para que premiase el mejor proyecto; sin embargo, tal concurso, según Wenceslao Álvarez, ${ }^{12}$ no llegó a realizarse debido a los problemas económicos que tenía la Institución.

Ante esta circunstancia, la Diputación acordó encargar en primer lugar el acondicionamiento del salón de sesiones al arquitecto Juan Bautista Lázaro. Desde 1880, su hermano José María Lázaro era diputado provincial, por lo que no es de extrañar que fuese él quien propusiese a su hermano para

\footnotetext{
${ }^{11}$ W. ÁLVAREZ OBLANCA, op. cit., p. 39.

12 Ídem.
}

acometer las reformas necesarias en el monumento dada su dedicación en intervenciones similares.

A la vez que desarrolló este primer proyecto para el palacio, cuyo contenido veremos a continuación, Lázaro publicó en la revista Anales de la Construcción y de la Industria tres artículos sobre este monumento. ${ }^{13}$ En ellos, además de plasmar cómo pudo ser la distribución inicial del edificio y de describir tanto las fachadas exteriores como el patio interior, aplaudía que la Corporación provincial hubiera adquirido dicho edificio para instalar en él sus oficinas y poder salvar así esta obra de arte de las injurias que el tiempo y la ignorancia le habían hecho sufrir. A su modo de ver, se trataba de un magnífico edificio, muy superior a cualquier otro que se hubiera podido levantar de nueva planta debido a la falta de criterio artístico que en aquella época existía para ejecutar grandes construcciones de esta índole. Instaba igualmente a la Diputación a que no paralizase la iniciada restauración de su nuevo palacio, "porque con ello prestará un verdadero servicio a las artes y conservará a la histórica ciudad de León un monumento que justamente se envanece de poseer" ${ }^{14}$ Desde el punto de vista constructivo destacaba Lázaro tres soluciones adoptadas en el patio interior por el constructor renacentista: $1^{\circ}$ la disposición de arcos diagonales para contrarrestar los empujes de las arcadas del cuerpo bajo; $2^{\mathrm{o}}$ la disposición invertida de los capiteles jónicos de las columnas de la galería baja para resolver fácilmente el encuentro en los ángulos; y 3ํㅜ la disposición en los ángulos de haces de tres columnas. Mencionaba asimismo que era digno de ver en el patio como los "buenos" arquitectos del renacimiento habían continuado el principio

\footnotetext{
${ }^{13}$ J. B. LÁZARO DE DIEGO, “Diputación de León”, Anales de la Construcción y de la Industria, no 13, julio 1884, pp. 201-202; no 17 , septiembre 1884, pp. 260-261; y no 24, diciembre 1884, pp. 376-377.

${ }^{14}$ J. B. LÁZARO DE DIEGO, “Diputación de León”, Anales de la Construcción y de la Industria, no 24, diciembre 1884, p. 377.
} 
artístico que fue origen de grandes bellezas en los siglos anteriores al de ejecutar esta construcción: la subordinación de las formas a las necesidades constructivas, de forma que la decoración venía a hacer más patente la construcción, en lugar de ser postizo adorno sin expresión ni sentido.

LOS PROYECTOS DE ADECUACIÓN DEL SALÓN DE SESIONES: UNA SOLUCIÓN FUNCIONAL PARA EL NUEVO USO

El 30 de junio de 1884, Lázaro presentó su proyecto de decorado del salón de sesiones de la Excelentísima Diputación provincial de León. En líneas generales, el proyecto definía el mobiliario necesario para las sesiones de la Corporación y la decoración que debía de tener como espacio principal del edificio.

Antes de ejecutar el proyecto, Lázaro llevó a cabo un reconocimiento de los elementos constructivos de la sala, percatándose que algunas de las viguetas de madera del forjado de techo no acometían correctamente en el muro de fachada, lo que le llevó a proponer en el proyecto la disposición de una viga carrera paralela a ésta que se dispondría sobre unas ménsulas de hierro fijadas al muro cada cierta distancia [Fig. 2]:15 las viguetas del forjado descansarían sobre la carrera nueva. Esta solución se adoptó por ser la más fácil y por presentar más ventajas de ejecución, no precisando de esta manera proceder a la demolición del forjado y su posterior reconstrucción.

La chimenea del testero merecía por su carácter artístico todo su respeto, pero como tenía un hogar de excesivas dimensiones era partidario de reducirlo [Fig. 3. № 3].

Además de las carpinterías de los tres huecos de balcón sumamente deterioradas,

\footnotetext{
15 Esta solución adoptada por Lázaro es por lo que el friso superior con los escudos de los partidos judiciales de la provincia está inclinado.
}

debía renovarse el pavimento del salón porque el existente no se correspondía con la importancia del uso que iba a tener la estancia. La sala la dividía en dos partes según su distribución [Fig. 3. № 1]: la parte destinada al público la planteaba con un entarimado de pino melis a corte de pluma, y en la parte destinada a los Diputados, que elevaba 0,45 m. respecto del nivel de la otra zona, el entarimado se dispondría a listón corrido.

Una vez se finalizasen estas obras, se comenzaría con su decoración, iniciándose con la limpieza y lijado de la madera de los techos, y con la reparación de todas las imperfecciones que presentasen, para proceder, a continuación, con la pintura y dorado de todas estas partes [Fig. 4]. Posteriormente, se recorrerían todos los muros hasta que quedasen planos, arreglándose la sobre-chimenea y haciéndose en escayola o pasta el dibujo que proponía para esta zona en uno de los planos del proyecto [Fig. 5]. Se pintarían todos los muros con cuatro manos al óleo en caso de que no se procediese al revestido de éstos con tapices o telas, no siendo partidario de la última solución mencionada, pues se deterioraba rápidamente por efecto de la luz solar. Si finalmente se optaba por instalar tapices, éstos se colocarían con arreglo a la distribución que se realizaría en un nuevo plano, disponiéndose a su alrededor una moldura de pino imitando a roble que posteriormente se barnizaría.

El zócalo se sujetaría -decía Lázaro- al diseño del plano adjunto [Fig. 6]. Este diseño, según he podido verificar en las investigaciones que para mi tesis doctoral vengo desarrollando sobre las intervenciones de restauración que llevó a cabo el arquitecto Lázaro en la catedral de León durante finales del siglo XIX y principios del siglo XX, aparenta estar inspirado en la cara interior de los entrepaños que existían y todavía existen en las puertas de la portada de S. Francisco del pórtico oeste. Este proceder no resultaría extraño, pues desde muy joven Lázaro manifestó su predilección por el principal templo 
de la ciudad. ${ }^{16}$ Años después, Lázaro volvería a emplear una variación de esta solución en el zócalo del retablo mayor de la catedral de León; e incluso, Juan Crisóstomo Torbado, ${ }^{17}$ efectuaría un nuevo zócalo para el retablo de la Quintanilla que se dispondría en el brazo norte del crucero de la seo leonesa, ${ }^{18}$ cuyo diseño sería prácticamente idéntico al que proyectó Lázaro para el salón de sesiones del palacio de los Guzmanes.

En cuanto al mobiliario de la sala, iluminación y aparatos de calefacción decía estar perfectamente definido en los planos adjuntos, con lo que no entraba a describirlos en la memoria del proyecto [Figs. 3, 7 y 8].

Finalmente, exponía en la memoria que todas las obras contenidas en el proyecto podían ejecutarse por subasta salvo la pintura de tapices, el aparato de calefacción, el decorado de la chimenea y demás elementos de ornamentación que deberían ser encargados por la Diputación provincial de forma privada.

En la sesión plenaria de la Diputación de León que se celebró el 21 de noviembre de 1884 y de la cual se daba cuenta en el Boletín Oficial de la Provincia de León del 17 de diciembre del mismo año, se acordó: aprobar este proyecto de Lázaro para el arreglo del salón de sesiones de la Corporación

\footnotetext{
${ }^{16}$ Esta predilección por la catedral de León ha sido expuesta en: E. M. REPULLÉS Y VARGAS, “Necrología de Juan Bautista Lázaro de Diego", Boletín de la Real Academia de Bellas Artes de San Fernando, no 52, 1919,
} pp. 257-258.

17 Según la real orden de 19 de julio de 1893 y la real orden de 1 de abril de 1900, Juan Crisóstomo Torbado fue el arquitecto auxiliar de las obras de la catedral de León durante gran parte del período de tiempo en el que Lázaro fue el arquitecto director de las mismas, sustituyéndole, tal como da cuenta Ignacio GonzálezVaras en su trabajo titulado La catedral de León. Historia y Restauración (1859-1901), como arquitecto director de éstas al comenzársele a manifestar a Lázaro los primeros síntomas de la enfermedad mental que varios años después acabaría con su vida.

${ }^{18}$ Actualmente se encuentra en la antigua capilla de Sta. Teresa sin el zócalo que proyectó Torbado. provincial, aprobar la subasta de las obras de carpintería y pintura que habían tenido lugar y que se habían adjudicado al contratista Gregorio Magdaleno, y encargar a Lázaro que dirigiese la ejecución de las obras por él proyectadas. Estas obras se fueron ejecutando durante los siguientes meses por el mencionado contratista, ${ }^{19}$ produciéndose algunas variaciones respecto del proyecto inicial por causa de la forma y procedimiento empleado para su realización, pues la necesidad de subastar elementos que por su índole no eran propicios de llevarse a cabo según este procedimiento, condujo la obra a unos términos tales que resultaron agrupados servicios heterogéneos y por tanto, difíciles de compaginar. ${ }^{20}$

Una vez concluida las obras de consolidación y de recuperación de los elementos arquitectónicos era necesario acometer la ornamentación y dotar de los objetos precisos para completar el decorado del salón de sesiones de la Excma. Diputación de León: mobiliario, calefacción, alumbrado, arreglo de estancias anexas, etc. Por ese motivo, Lázaro llevaría a cabo un nuevo proyecto en el que incluiría todas esas obras bajo el título de proyecto de terminación de las obras del Salón de Sesiones de la Excma. Diputación de León y que firmó el 11 de septiembre de 1885.

En este último proyecto mencionado, y en vistas de la futura liquidación que debería acometer, Lázaro procedería a englobar en el presupuesto los distintos trabajos por oficios.

19 Tenemos constancia de ello ya que se aprobó en la sesión plenaria del 13 de abril de 1885 una certificación que había presentado Lázaro con las obras ejecutadas por Gregorio Magdaleno. Véase "Extracto de la sesión del día 13 de abril de 1895", Boletín Oficial de la Provincia de León, nº 139, 20-05-1885, p. 3.

20 En la memoria del proyecto que tiempo después redactó para la terminación de las obras del salón de sesiones expuso la problemática de contratar todas las obras por subasta cuando algunas de ellas no eran adecuadas de acometer según el mencionado procedimiento. 
La decoración que en el primero de los proyectos para el salón de las sesiones estaba prevista esculpida, proponía sustituirla por decoración pintada como consecuencia de las condiciones de luz observadas en el salón después de las obras ya ejecutadas y al objeto de evitar dilaciones.

En cuanto al resto de los elementos, Lázaro no consideraba suficiente la definición que de éstos había reflejado en los planos de su primer proyecto para que fuesen correctamente ejecutados, entendiendo que era necesario facilitárselos a tamaño natural o bien presentarles a los operarios que los fuesen a llevar a cabo modelos ya realizados. Otros de ellos se elegirían entre los disponibles en los comercios del ramo.

Las cartelas con escudos de armas de los partidos de la provincia a disponer en el friso alto conservarían el carácter de los que había en los antepechos del patio del palacio. ${ }^{21}$ Definía cómo se deberían de pintar los testeros norte y sur del salón, y proponía además forrar de papel la antesala y blanquear el pasillo de la portería. En cuanto a la iluminación, proyectó colocar grupos de cinco luces de bujía de latón en diez pilastras de la sala y en los tres huecos de la fachada se pondrían vidrieras que formasen combinaciones geométricas agradables y con carácter de época.

A la terminación de la plataforma elevada y en la delantera del balcón se colocaría un antepecho formado por tres barras de latón dorado o niquelado arriostradas por otros dos horizontales.

Meses antes de este proyecto, el 2 de julio de 1885, Lázaro redactó el pliego de condiciones facultativas con arreglo a las cuales debía de llevarse a cabo la ejecución de los tapices a disponer en el salón de plenos. En él se especificaban los

\footnotetext{
21 En efecto, el paralelismo entre la decoración de los antepechos del patio del palacio y las cartelas decorativas superiores de la sala de sesiones que existieron hasta hace unos años era más que evidente.
}

asuntos que deberían figurar en cada uno de ellos, y exponía que sus dimensiones se determinarían a partir de los elementos arquitectónicos que constituían la decoración general del salón, y de cuyas dimensiones se descontarían las cenefas decorativas que se dispondrían con el carácter y dibujo propio del siglo XVI. Asimismo planteaba que se tomasen como modelos los existentes en el Palacio Real por representar temas análogos a los aquí requeridos, especificando que la indumentaria y epigrafía debía basarse en la de los tapices propios de la época a la que el edificio pertenecía, investigando si las referencias eran adecuadas o no al examinar los detalles escultóricos del patio y de sus fachadas. No olvidó incluir en los artículos del pliego cómo debían ejecutarse estos tapices y cómo debían colocarse en la propia sala.

Tras la correspondiente convocatoria de subasta, los trabajos fueron encargados al artista Francisco Amérigo, según recoge Wenceslao Álvarez en su guía sobre el palacio. $^{22}$

Estas obras de acabado del salón de sesiones se encontraban a punto de finalizarse en abril de 1886, no habiéndose terminado antes ya que por enfermedad Lázaro no había podido facilitar al contratista algunos detalles indispensables para el remate de las obras, tal como se dio cuenta en la sesión provincial que tuvo lugar el 14 del mencionado mes y año.

El aspecto general que debió de presentar el salón de sesiones tras acometer Lázaro su acondicionamiento debió ser prácticamente igual al que se refleja en la fotografía adjunta [Fig. 9], según resulta de comparar la lámina fotográfica mencionada y el contenido de lo reflejado en los distintos proyectos que respecto del salón de sesiones suscribió Lázaro y que se han desarrollado con anterioridad.

\footnotetext{
22 W. ÁLVAREZ OBLANCA, op. cit., p. 39.
} 


\section{EL PROYECTO DE ACONDICIONAMIEN- TO DEL PALACIO DE LOS GUZMANES: LOS CRITERIOS DE INTERVENCIÓN}

Lázaro no sólo redactó los proyectos del salón de sesiones expuestos, sino que también realizó un proyecto de acondicionamiento general del edificio con las obras de reparación y terminación necesarias para todo el palacio de los Guzmanes, tras descartar por irrealizable la Diputación Provincial de León la convocatoria de un concurso público para las obras de terminación del palacio provincial, tal como habían aprobado en la sesión del 22 de noviembre de 1884. La Asamblea Provincial, en la sesión que celebró el 20 de abril de 1885, acordó encargar a Lázaro la elaboración de este proyecto, ordenándole al arquitecto redactor a que lo subdividiese por anualidades al objeto de que el coste de las obras previstas para cada año no excediese de la consignación anual fijada en el presupuesto de la corporación provincial de cada uno de los años económicos en que se preveían llevar a cabo estos trabajos. Una vez que le comunicaron el encargo el 24 de abril, Lázaro tardó varios meses en su redacción ya que hasta noviembre del mismo año no lo presentó. El programa que le requirieron no se reducía únicamente a disponer de forma definitiva todos los espacios necesarios para cada uno de los departamentos de la Diputación Provincial de León, sino también a ubicar dentro del edificio los espacios necesarios para albergar las oficinas de la Hacienda Pública, logrando así dicha institución un renta nada despreciable.

Sin analizar el estudio de la distribución que proyectó para las dependencias de la Diputación de León por no ser objeto de este trabajo [Fig. 10], sí es de reseñar que para su ejecución precisaba previamente acometer la demolición de las distribuciones existentes y realizadas según las necesidades de uso que tenía el palacio antes de su adquisición para sede provincial [Fig. 11].

Antes de exponer las obras necesarias para reparar los desperfectos que el edificio presentaba y las necesidades que requerían cada una de las estancias para el uso previsto, Lázaro consideraba conveniente adquirir el solar del ángulo nordeste, e imprescindible deslindar las servidumbres de luces y aguas que disfrutaba el solar del palacio por su costado norte antes de comenzar las obras.

En cuanto a las obras que planteaba en el proyecto, en primer lugar, consideraba necesario proceder al derribo de toda la crujía norte y su accesoria en escuadra, por no haberse seguido en su ejecución las buenas prácticas de construcción y por estar en tan deplorable estado de conservación que todo esfuerzo para repararlas debidamente sería infructuoso. Además en la intersección de ambas crujías subsistía un trozo de la antigua muralla cuya presencia impedía tanto el aprovechamiento del local que ocupaba, como revelaba la no terminación de la obra por aquella parte.

Estas dos crujías que proponía derribar y volver a reconstruir serían las primeras obras a realizar ya que en ellas preveía construir la nueva escalera que comunicaría todas las plantas. Para que fuese posible iniciar esta intervención era preciso disponer la habitación del Conserje en el ángulo sudeste del edificio, lo cual exigía abrir un hueco y la ejecución de algunos tabiques, así como la reparación de la antigua escalera de servicio.

A estas obras necesarias de carácter funcional, le seguirían otras no menos indispensables por razón de solidez y decoro artístico: la consolidación de los pisos y techos de las galerías del patio, las recogidas de las aguas pluviales, y todas las armaduras y cubiertas del palacio. Finalizadas éstas, se pasarían a realizar las obras que, a pesar de no ser indispensables para la consolidación del edificio, sí serían necesarias para evitar su deterioro y para lograr el decoro que el palacio requería: el arreglo y decoración de los dos accesos al monumento, el arreglo de los pavimentos, muros y elementos del patio, el de la escalera principal, el de las estancias y 
locales destinados a las oficinas de la Diputación y finalmente el recalce de sus fachadas. En último lugar contemplaba las obras de distribución y ornato que eran necesarias acometer para instalar las oficinas de la Delegación de Hacienda, y las de terminación de las torres de la fachada oeste absurdamente mutiladas por el P. Echano en torno a 1840 y que estaban ruinosamente cubiertas. ${ }^{23}$

El orden de ejecución de las obras propuestas no era caprichoso y arbitrario, sino que respondía a la necesidad de que el edificio se fuese transformando sucesivamente sin que las diversas dependencias de la Diputación dejasen de prestar su servicio público, esto es, se llevarían a cabo las obras a la vez que parte del edificio seguía atendiendo las necesidades de los ciudadanos de la provincia. El derribo de la crujía norte y el de sus construcciones anexas podía comenzarse una vez que se trasladasen las dependencias del conserje a su nueva ubicación, pues los locales donde se encontraban instaladas las oficinas de Hacienda habían sido ya desocupados en aquella época. Finalizado el derribo y llevada a cabo la nueva construcción, se ubicarían en ella las oficinas de instrucción pública y obras, desalojándose así la galería alta del patio para acometer las obras necesarias en ella y el cerramiento acristalado de la misma. Concluidas las obras de la galería habría suficiente superficie de locales para desahogar todas las demás dependencias y poder realizar en ellas las modificaciones propuestas por Lázaro en los planos. Por último, se habilitarían los locales destinados a la Delegación de Hacienda.

\footnotetext{
${ }^{23}$ En el segundo de los tres artículos que sobre este edificio publicó en el número 17 (septiembre 1884) de la revista Anales de la Construcción y de la Industria bajo el título "Diputación de León", Lázaro exponía que por fortuna habían quedado bastantes elementos que permitían la restauración de las dos torres de la fachada de poniente, añadiendo que la traza de la arquería final de las torres tuvo que ser originalmente muy semejante al trazado de las existentes en la galería del cuerpo alto de la fachada de poniente. Con esta intervención decía que se contribuiría sobremanera a la hermosura y majestad del conjunto.
}

En cuanto a la calefacción decía no poder acudir a los sistemas de más reconocido éxito por aquel entonces, pues, debido a la existencia del patio central, se tendría que recurrir a dos o tres focos caloríferos, siendo su coste excesivo; además la necesidad de aprovechar los sótanos desde el punto de vista funcional impedía emplearlos para calefactar el edificio, aunque la disposición planteada no era impedimento para que se llevase a cabo si posteriormente así se decidía. Añadía que la distribución no podía ser otra y que no estaba dispuesto a consentir, porque el decoro del palacio provincial así lo exigía, que se siguiese utilizando la parte baja porticada del palacio como almacén para cajas de tabacos y papel sellado, ya que impedía la contemplación de esta parte del edificio y deterioraba las partes bajas de sus muros y todo el pavimento.

Por último, al tratarse de un edificio de carácter artístico, exponía sus criterios sobre cómo debía de intervenirse en las zonas del edificio que presentaban carácter artístico y que, a su juicio, eran sus fachadas y patio. Se oponía al sistema de retoques y remiendos con que se creía realizar una restauración, ya que de esa forma se lograba solo hacer más patentes los desperfectos de la antigua obra. En cambio, proponía "no reparar bajo ningún pretexto más que aquello que ofreciese peligro de ruina, reconstruyendo y restableciendo con la posible fidelidad y donde subsisten datos para ello las antiguas disposiciones". ${ }^{24}$ Es decir, que sólo proponía intervenir en aquellas partes que amenazasen ruina, volviéndose a reconstruir tal como se encontraban o tal como habían sido si existía documentación suficiente para su reconstrucción. Por lo demás, manifestaba que el hecho de que "una cornisa tenga o presente sus aristas desportilladas, que un miembro decorativo esté más o menos deteriorado, que se halle más o menos alterado en color o en detalle por la acción del tiempo, no

\footnotetext{
24 J. B. LÁZARO DE DIEGO, Proyecto general de las obras de reparación y terminación del palacio Provincial de León. [Memoria descriptiva], ms., Madrid, 9-11-1885, p. 10, Archivo Diputación de León, 20083/1.
} 
son a mi juicio razones bastantes para proceder a su sustitución por otro nuevo que siempre resultaría desabrido y probablemente falto de carácter". ${ }^{25}$ Estas ideas eran completamente diferentes a las que Demetrio de los Ríos estaba aplicando en las obras de restauración que dirigía en la catedral de León en aquel entonces. ${ }^{26}$ Por ese motivo, cuando Lázaro formó parte de la Comisión Inspectora de las obras que se desplazó a León en 1887 para informar acerca del estado de las mismas, así como para proponer cuanto condujese a terminarlas en el plazo más breve posible, no es de extrañar que sus miembros propusiesen a de los Ríos que sólo interviniese en las partes que estaban deterioradas y no en el resto como venía realizando hasta aquellos días al objeto de lograr la "unidad de estilo" del templo. ${ }^{27}$ Esta propuesta, según los estudios llevados a cabo para mi tesis doctoral, fue el motivo por el que los pináculos, crestería, cornisa, rosas ciegas, enjutas y gabletes correspondientes a los ventanales altos del ábside de la catedral de León no fueron sustituidos por los que había ejecutado años antes de los Ríos en el resto de la nave mayor y ambos brazos del crucero.

Estos planteamientos eran muy innovadores para aquellos años en España, pues los procedimientos habitualmente seguidos por los arquitectos restauradores bebían de los principios de la "restauración estilística" planteada por Viollet-le-Duc; sin embargo, su planteamiento se inclinaba hacia posturas más conservadoras: actuaciones imprescindibles para hacerlo habitable para

25 Ídem.

26 Sobre las obras de restauración de la catedral de León que tuvieron lugar en la segunda mitad del siglo XIX, véase: J. RIVERA BLANCO, Historia de las restauraciones de la catedral de León, Valladolid, 1993; e I. GONZÁLEZ-VARAS IBAÑEZ, La catedral de León. Historia y restauración (18591901), León, 1993.

27 Este informe se conserva en la $2^{\underline{a}}$ parte del expediente 8842-1 existente en la caja 31/08055 del fondo (05)014-002 del Archivo General de la Administración situado en Alcalá de Henares, existiendo en el mismo legajo un documento que prueba que el contenido del informe fue aprobado por real orden del 20 de enero de 1888 . su nueva función e interviniendo sólo en aquellos elementos artísticos que estuviesen en peligro de ruina. De forma que sus ideas se encontraban a mitad de camino entre John Ruskin y Viollet-le-Duc, siendo totalmente conformes con los postulados de "acción mínima" desarrollados por Camilo Boito, a quien Lázaro, según $\mathrm{M}^{\mathrm{a}}$ Dolores Campos Sánchez Bordona, admiraba. ${ }^{28}$

Este proyecto de acondicionamiento presentado por Lázaro fue aprobado en el pleno provincial que tuvo lugar el 12 de noviembre de 1886, acordando eliminar en aquel momento la parte del mismo que hacía referencia a la distribución y decoración interior de la parte destinada a las oficinas de Hacienda. Una vez aprobado, Lázaro efectuó en diciembre de 1886 el pliego de condiciones facultativas y económicas para sacar a subasta la realización de estos trabajos. Entre todas las condiciones expuestas en este pliego sobre los materiales y el proceso de ejecución de estas obras, es de reseñar que emplease la construcción de bóvedas tabicadas; solución constructiva poco habitual en la mayor parte de España salvo en Cataluña.

En relación con la ejecución de este proyecto de Lázaro, ${ }^{29}$ tenemos conocimiento que, tal como se había previsto, en primer lugar, se subastaron los trabajos incluidos en la primera fase del proyecto, cuyas obras debieron de ejecutarse entre 1887 y 1888, desconociendo si fue el mencionado arquitecto el director de esos trabajos. Una vez se concluyeron éstos, salieron a subasta las obras previstas en el segundo de los presupuestos incluidos en el proyecto, que comprendían las armaduras y cubiertas de tres alas del palacio, y los "pisos" y cerramientos de las

28 M. D. CAMPOS SÁNCHEZ-BORDONA, "Las transformaciones de la arquitectura señorial...", p. 183.

29 Toda la información sobre la ejecución del proyecto de Lázaro ha sido deducida de una noticia que sobre las obras del palacio de los Guzmanes apareció publicada en el periódico local El Porvenir de León. Véase: El Porvenir de León, no 2.705, 6-11-1889, p. 2. 
galerías. Estas obras de la segunda subasta estaban ya terminadas a comienzos de noviembre de 1889, habiendo sido ejecutadas bajo la dirección del arquitecto provincial Francisco Blanch y Pons. A partir de entonces, el arquitecto provincial se encargaría de continuar con las obras del proyecto de Lázaro y de otras nuevas.

\section{EN TORNO AL PALACIO DE LOS GUZ- MANES Y SU AISLAMIENTO}

La Diputación mostró en varias ocasiones la voluntad de lograr dejar exento el palacio. Por este motivo, en 1889 compró la servidumbre de luces y vistas sobre el jardín de la casa $\mathrm{n}^{\mathrm{o}} 5$ de la calle del Cid, al objeto de proteger el edificio histórico. Sin embargo, ese deseo se vio frustrado cuando a finales de 1891 Mariano Andrés y los herederos de Simón Fernández solicitaron licencia para edificar en el solar que estaba delante de la fachada oeste del palacio. A pesar de los esfuerzos llevados a cabo por los diputados José María Lázaro y Manuel Gutiérrez, quienes presentaron en 1892 un recurso ante el Ministro de Gobernación, éstos no consiguieron parar la edificación proyectada y al poco tiempo comenzaron las obras de la hoy conocida "Casa Botines" del arquitecto Antonio Gaudí.

Este deseo de los diputados también era compartido por la Comisión provincial de Monumentos de León, quién enterada de las intenciones de edificar delante del palacio de los Guzmanes acordó en su sesión del 3 de septiembre de 1891 oponerse a tal construcción, ya que privaba "a tan notable edificio de la preciosa vista que por aquella parte [fachada principal] ofrece" ${ }^{30}$

A raíz de las intervenciones propuestas por Lázaro en sus proyectos para el

\footnotetext{
${ }^{30}$ Libro de actas de la Comisión Provincial de Monumentos históricos y artísticos de León, ms., 3-9-1891, p. 59v, Biblioteca Pública de León, C.M. 615.
}

palacio de los Guzmanes podemos concluir que el mencionado arquitecto leonés no era partidario de actuar en las partes artísticas alteradas del edificio, salvo que ofreciesen peligro de ruina, proponiendo, en ese caso, su reconstrucción tal como se encontraban o bien tal como habían sido si existía documentación suficiente para su recuperación. Fiel a este criterio, Lázaro era partidario de que las pérdidas parciales de sillería, los pequeños deterioros de los elementos decorativos o las ligeras variaciones de color por el paso del tiempo no eran razón suficiente para su sustitución, ya que ésta desentonaría y resultaría falta de carácter, y sólo serviría para acentuar aún más los desperfectos de las antiguas fábricas. Por estos motivos, en estos últimos casos, prefería conservarlos tal como se encontraban.

En relación al resto de construcciones anexas del palacio que no presentaban valor artístico, Lázaro era partidario de derribar aquellas actuaciones que por su pésimo estado de conservación y su alto coste de restauración atentaban contra las condiciones artísticas y decoro del edificio.

En cuanto a los tratamientos de acabado interior, los nuevos elementos a disponer se harían acordes con la época a la que el edificio pertenecía, por eso Lázaro indicaba que para el Salón de Sesiones los tapices se realizasen con la indumentaria y epigrafía típica de la época del edificio y las cartelas de los escudos de armas de los partidos de la provincia se ejecutasen teniendo como modelo los existentes en los antepechos del patio; y aquellos elementos de las estancias que no fueran dignos del nuevo uso los sustituiría por otros más funcionales y efectivos.

Los criterios y planteamientos que empleó Lázaro en sus proyectos de intervención en el palacio de los Guzmanes fueron consecuentes con los criterios que sobre restauración y conservación de conjuntos monumentales había expuesto en los artículos titulados "el criterio artístico" y que 
fueron publicados en $1884 .{ }^{31}$ A su modo de ver, todo arquitecto restaurador debía tener dos cualidades: en primer lugar, un profundo respeto a los monumentos, por lo que en ningún caso se debería de emplear la piqueta en las intervenciones, salvo que presentasen indudables señales de ruina inminente; y en segunda lugar, la humildad artística, es decir, deponer las opiniones personales ante lo que el monumento es y significa. Por ello, el arquitecto restaurador debía estudiar, examinar y disecar el monumento que se le confiaba, por lo que era partidario de que no se siguiese ninguna escuela de restauración, pues todas pecaban de dejarse llevar por la forma y no por lo verdaderamente importante: la estructura. Además respecto de la primera cualidad añadía que todo lo que tuviese carácter monumental ya fuese de buen o mal gusto, que estuviese ligado con la historia y con las vicisitudes del edificio al que perteneciese tenía que ser conservado, por lo que valoraba no sólo el aspecto artístico del edificio sino también el histórico.

En lo que respecta al primero de los criterios queda patente, después de lo ya mencionado, que éste fue utilizado por Lázaro en sus propuestas de intervención para el palacio, a excepción de la parte de la muralla que se encontraba en la confluencia de las dos crujías donde propuso su demolición sin describir su estado ni especificar si se encontraba en ruina, y únicamente justificándolo por motivos funcionales. En cuanto al segundo de los criterios, tenemos constancia que Lázaro llevó a cabo un estudio previo del monumento antes de realizar sus propuestas de intervención en los proyectos que redactó para el palacio de los Guzmanes.

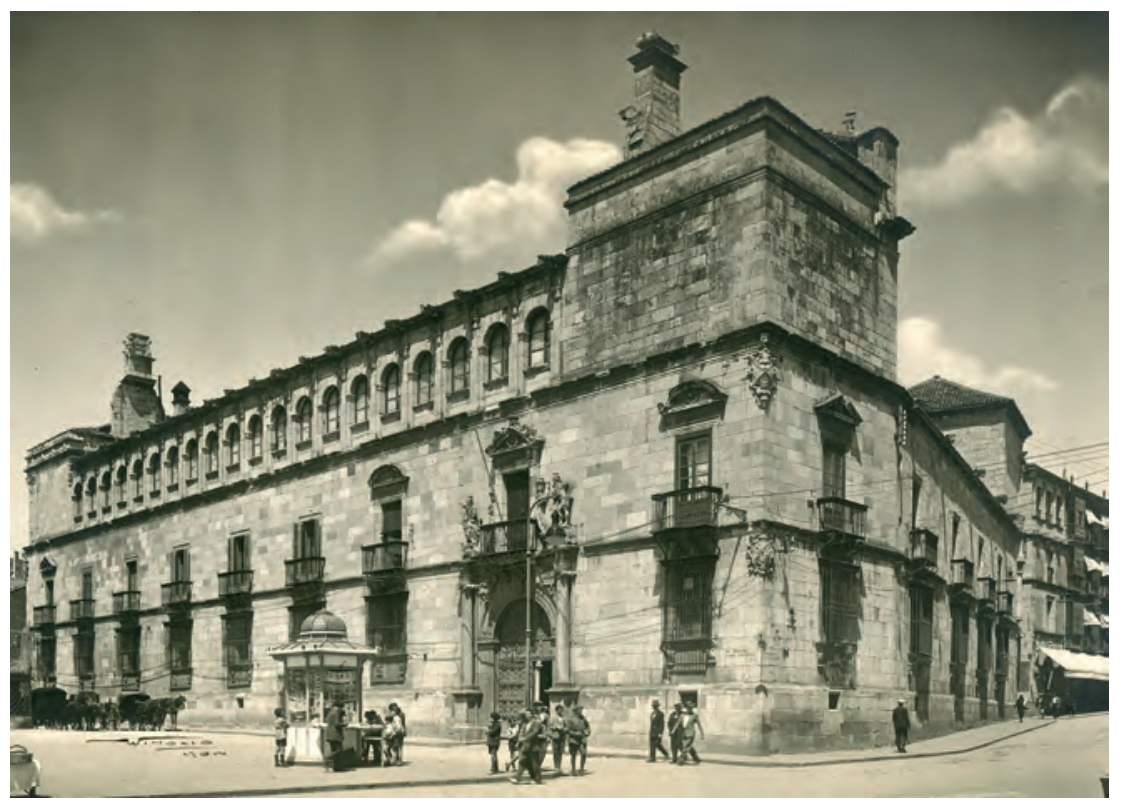

- Fig.1. W. TESTERA PÉREZ: Vista exterior del palacio de los Guzmanes varios años después de las intervenciones realizadas por Lázaro (Fragmento) [UVa. ETSAV. Biblioteca. Fondo Torbado].

31 J. B. LÁZARO DE DIEGO, "El criterio artístico", Revista de la Sociedad Central de Arquitectos, t. X, 10 septiembre 1884, pp. 193-195; t. X, 20 septiembre 1884, pp. 202-204; t. X, 20 noviembre 1884, pp. 253-256; y t. X, 30 noviembre 1884 , pp. 258-260. 


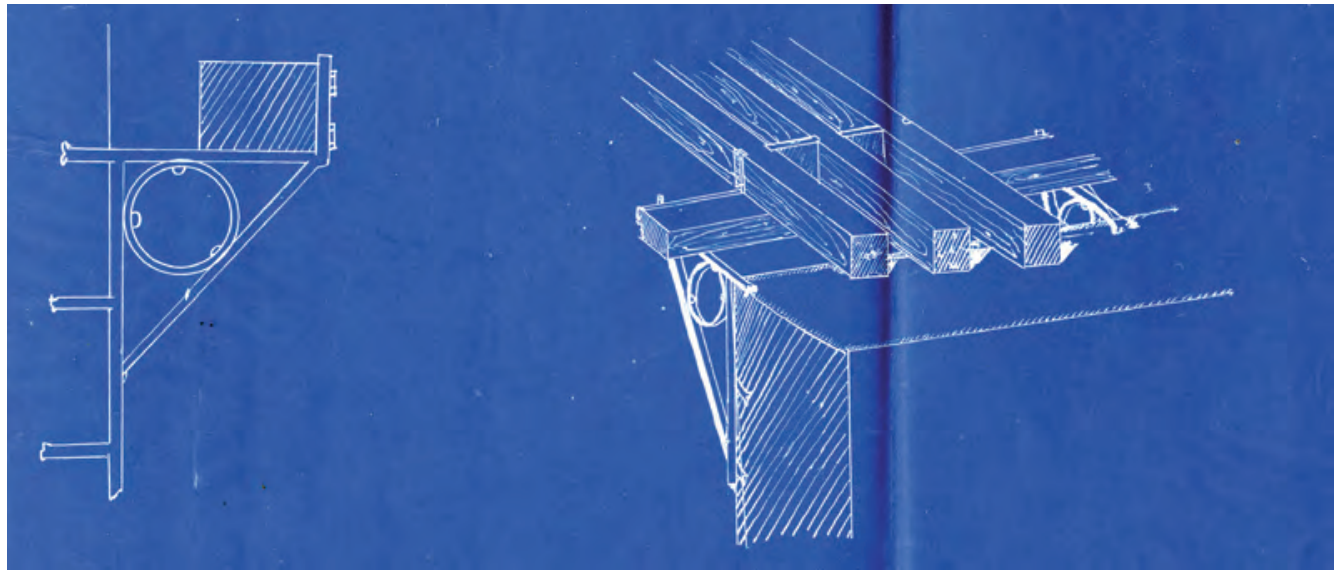

- Fig.2. J. B. LÁZARO DE DIEGO: Detalle de la propuesta para resolver los problemas de entrega de las vigas del forjado en el muro de fachada (junio 1884) (Fragmento) [Archivo Diputación de León. 20083/1. E.4-2].

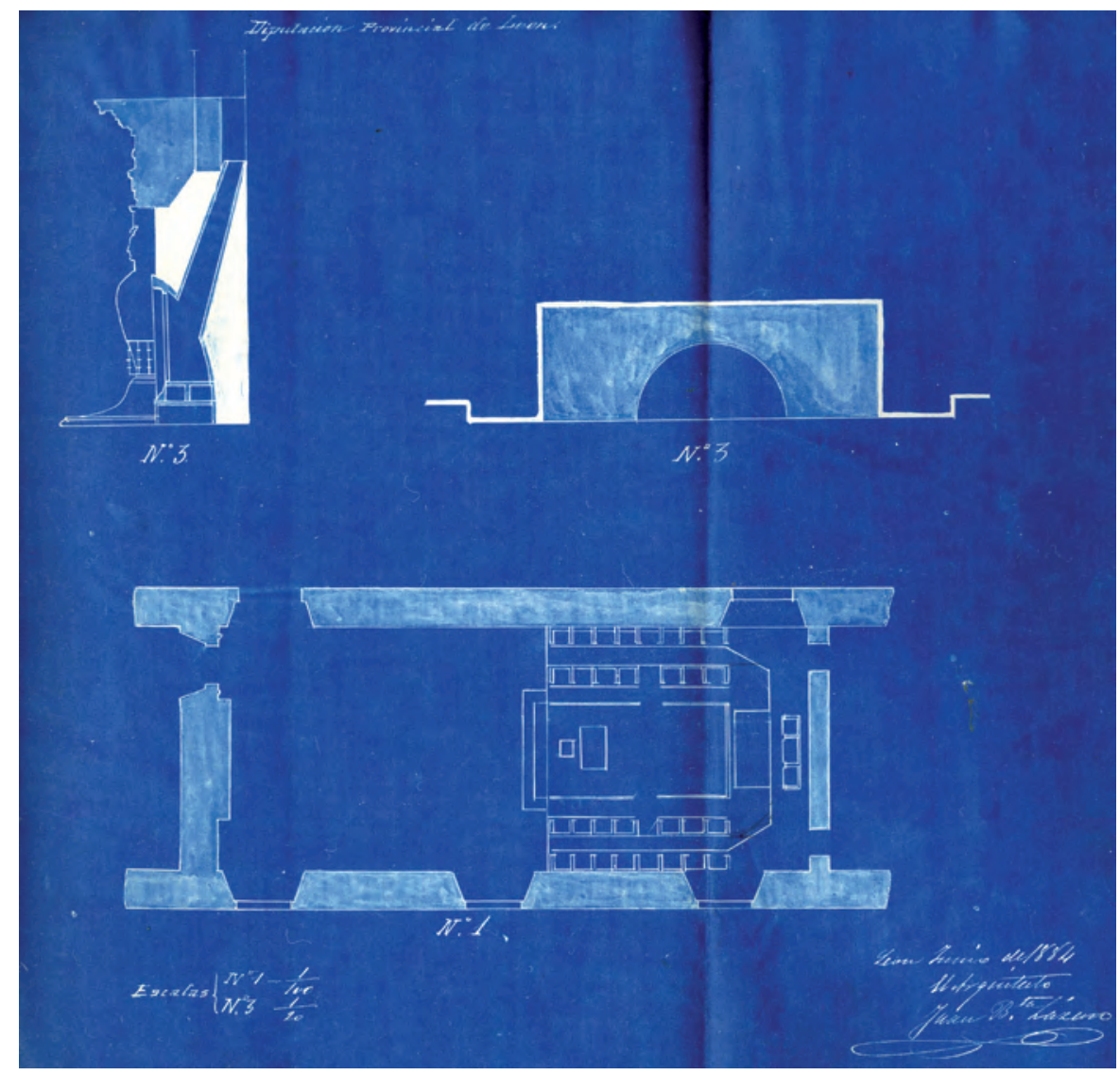

- Fig.3. J. B. LÁZARO DE DIEGO: Planta con la disposición adoptada por Lázaro para la colocación de los asientos de los diputados, y alzado y sección de la solución que planteó para la chimenea (junio 1884) [Archivo Diputación de León. 20083/1. E.4-2]. 


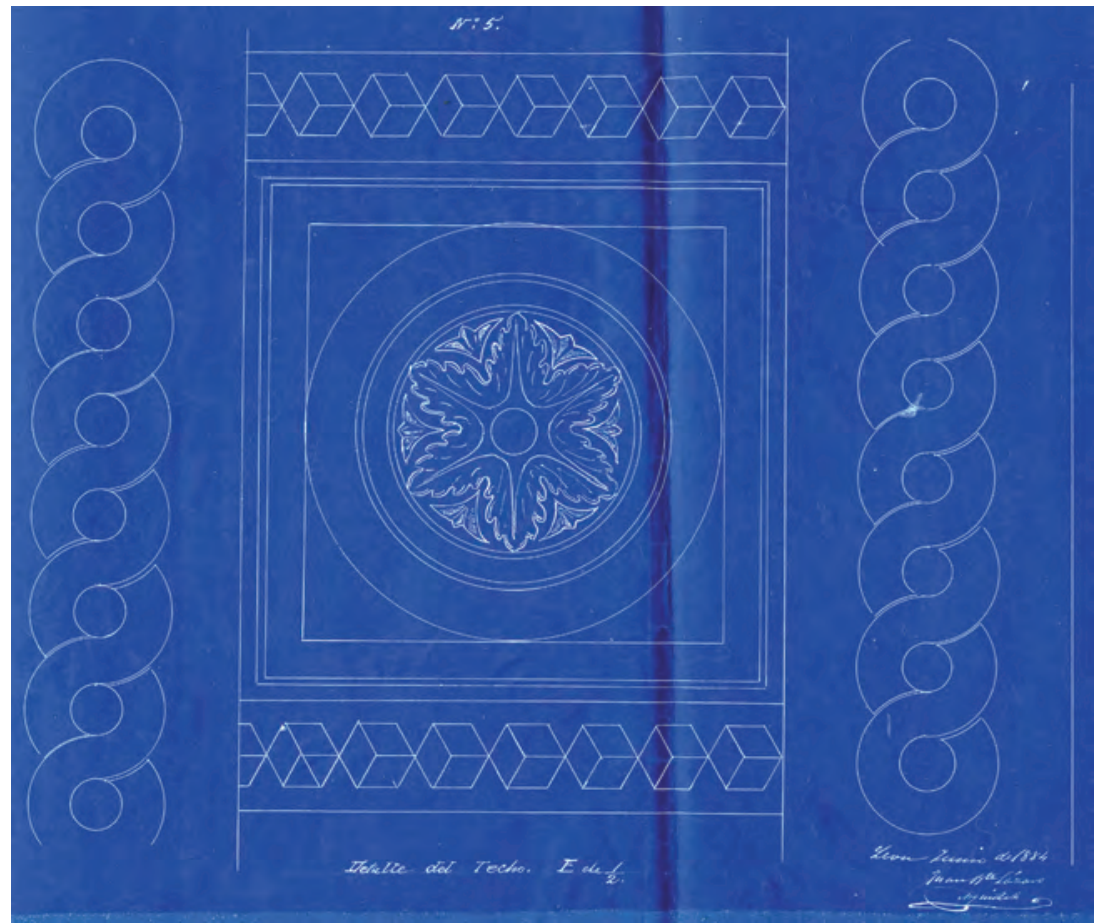

- Fig.4. J. B. LÁZARO DE DIEGO: Detalle de la pintura decorativa del alfarje propuesto para el salón de sesiones del palacio de los Guzmanes (junio 1884) [Archivo Diputación de León. 20083/1. E.4-2].

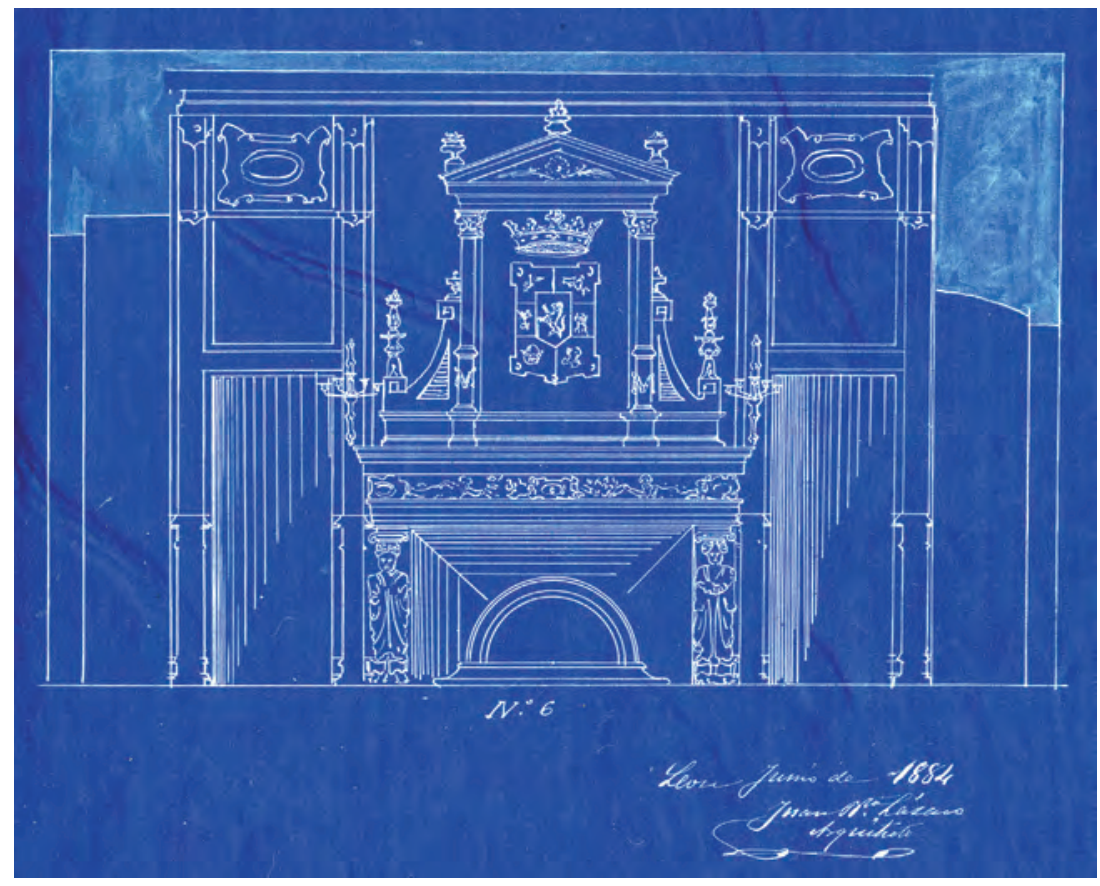

- Fig.5. J. B. LÁZARO DE DIEGO: Alzado del testero norte de la sala de sesiones con la propuesta decorativa efectuada por Lázaro (junio 1884) [Archivo Diputación de León. 20083/1. E.4-2]. 


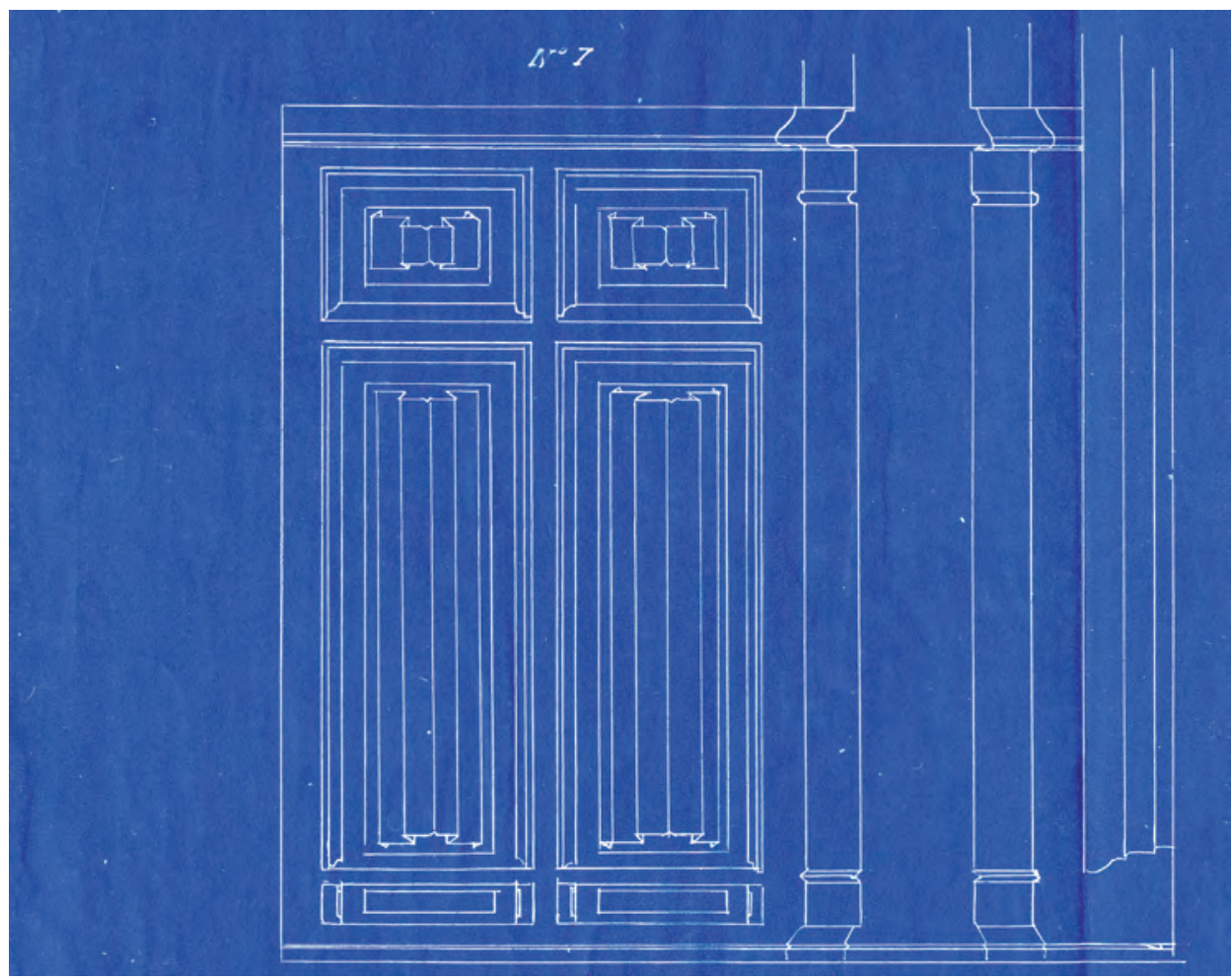

- Fig.6. J. B. LÁZARO DE DIEGO: Alzado del zócalo propuesto por Lázaro en el salón de sesiones del palacio de los Guzmanes (junio 1884) (Fragmento) [Archivo Diputación de León. 20083/1. E.4-2].

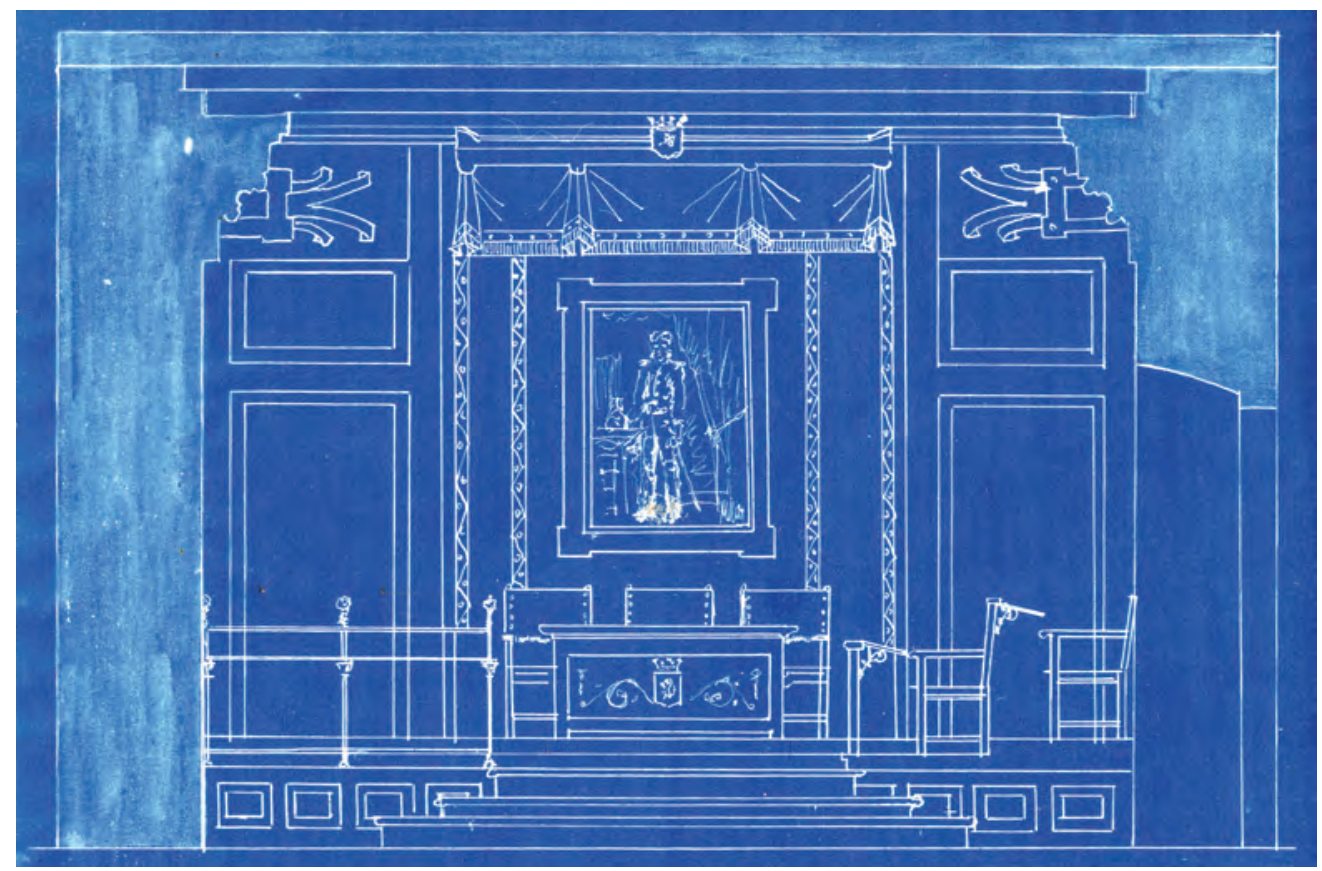

- Fig.7. J. B. LÁZARO DE DIEGO: Alzado del testero sur de la sala de sesiones con la propuesta decorativa efectuada por Lázaro (junio 1884) (Fragmento) [Archivo Diputación de León. 20083/1. E.4-2]. 


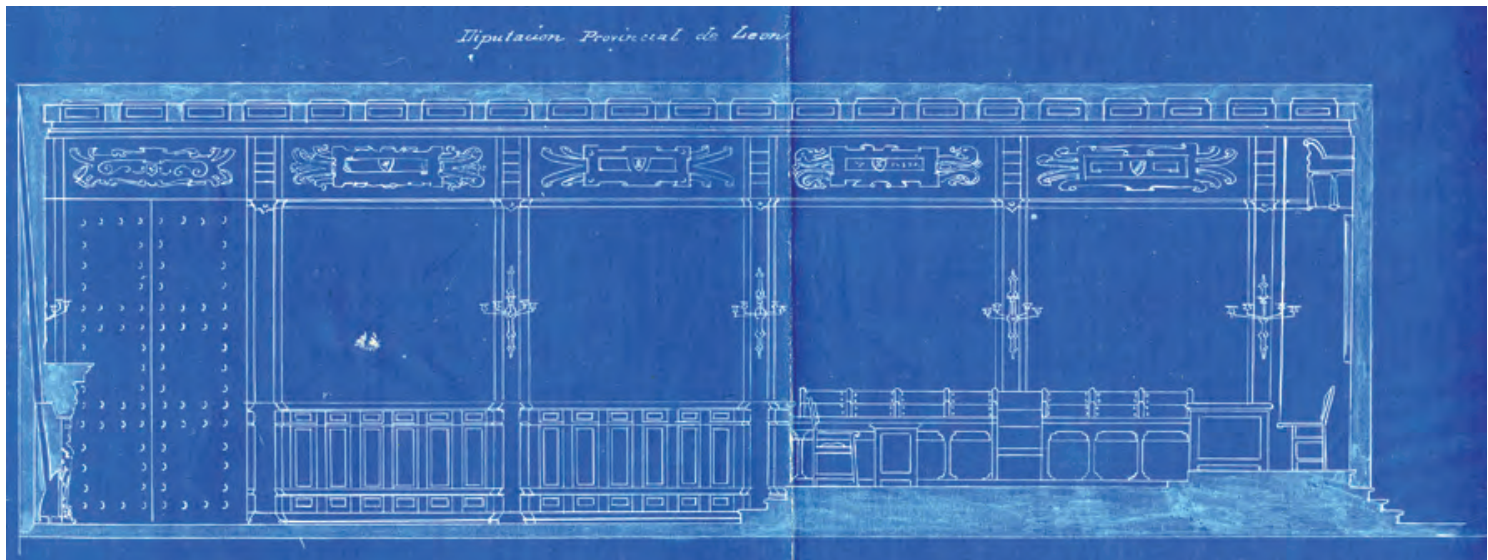

- Fig.8. J. B. LÁZARO DE DIEGO: Alzado del testero este de la sala de sesiones con la propuesta decorativa efectuada por Lázaro (junio 1884) (Fragmento) [Archivo Diputación de León. 20083/1. E.4-2].

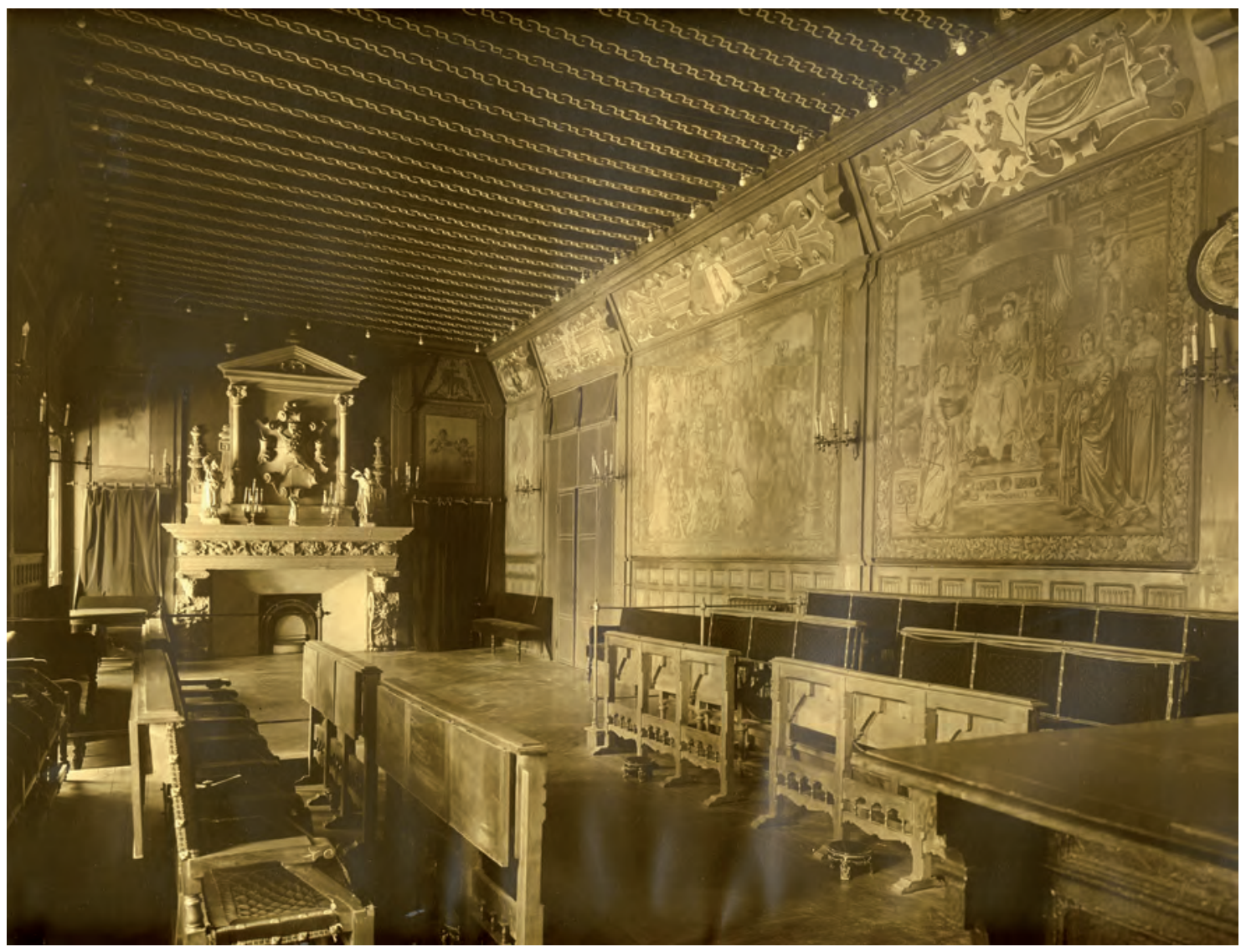

- Fig.9. [W. TESTERA PÉREZ]: Vista interior del salón de sesiones varios años después de su ejecución por Lázaro [UVa. ETSAV. Biblioteca. Fondo Torbado]. 

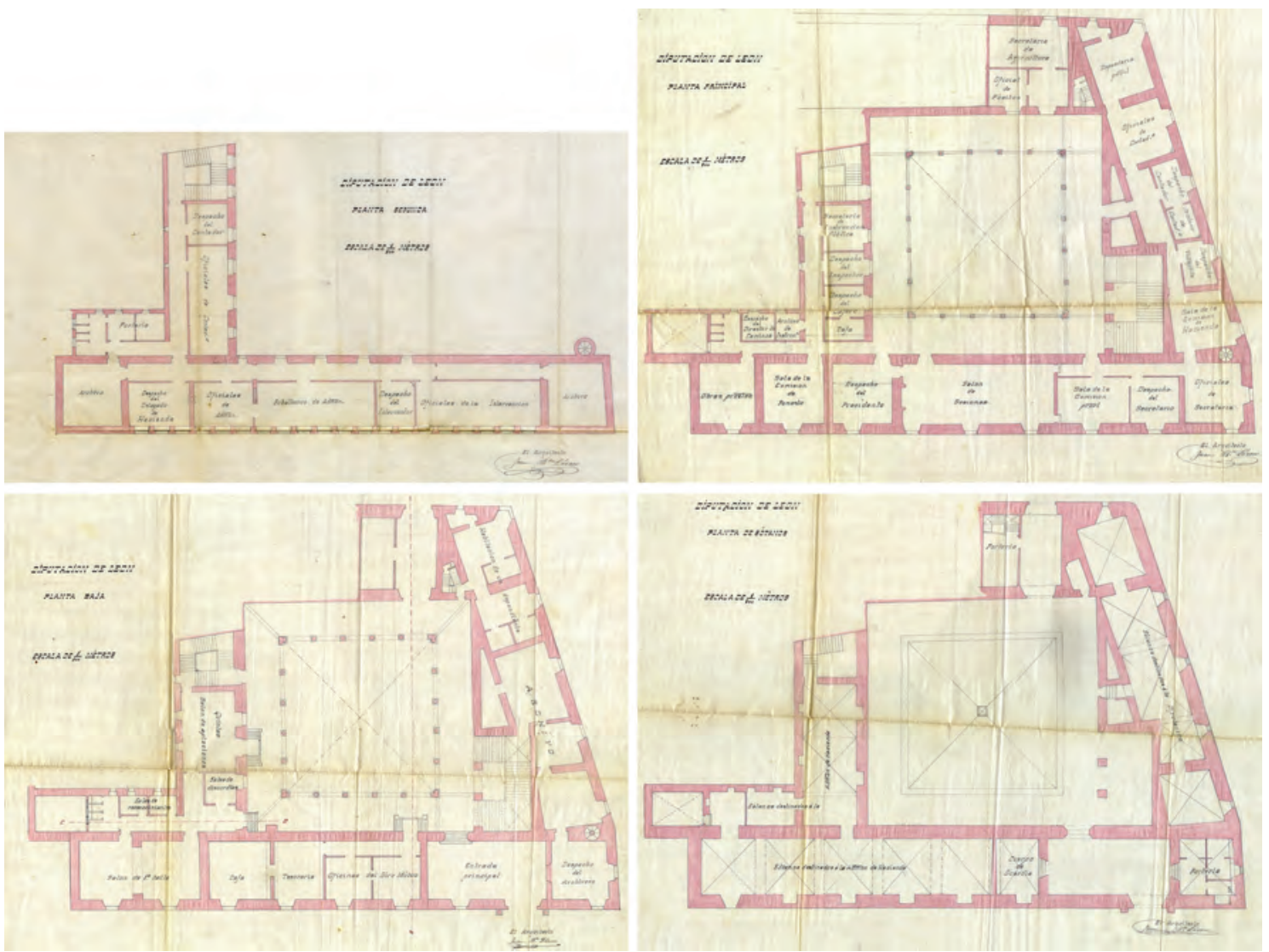

- Fig.10. J. B. LÁZARO DE DIEGO: Plantas con la nueva propuesta de distribución del palacio de los Guzmanes (9 noviembre 1885) [Archivo Diputación de León. 20083/1. E.4-1].

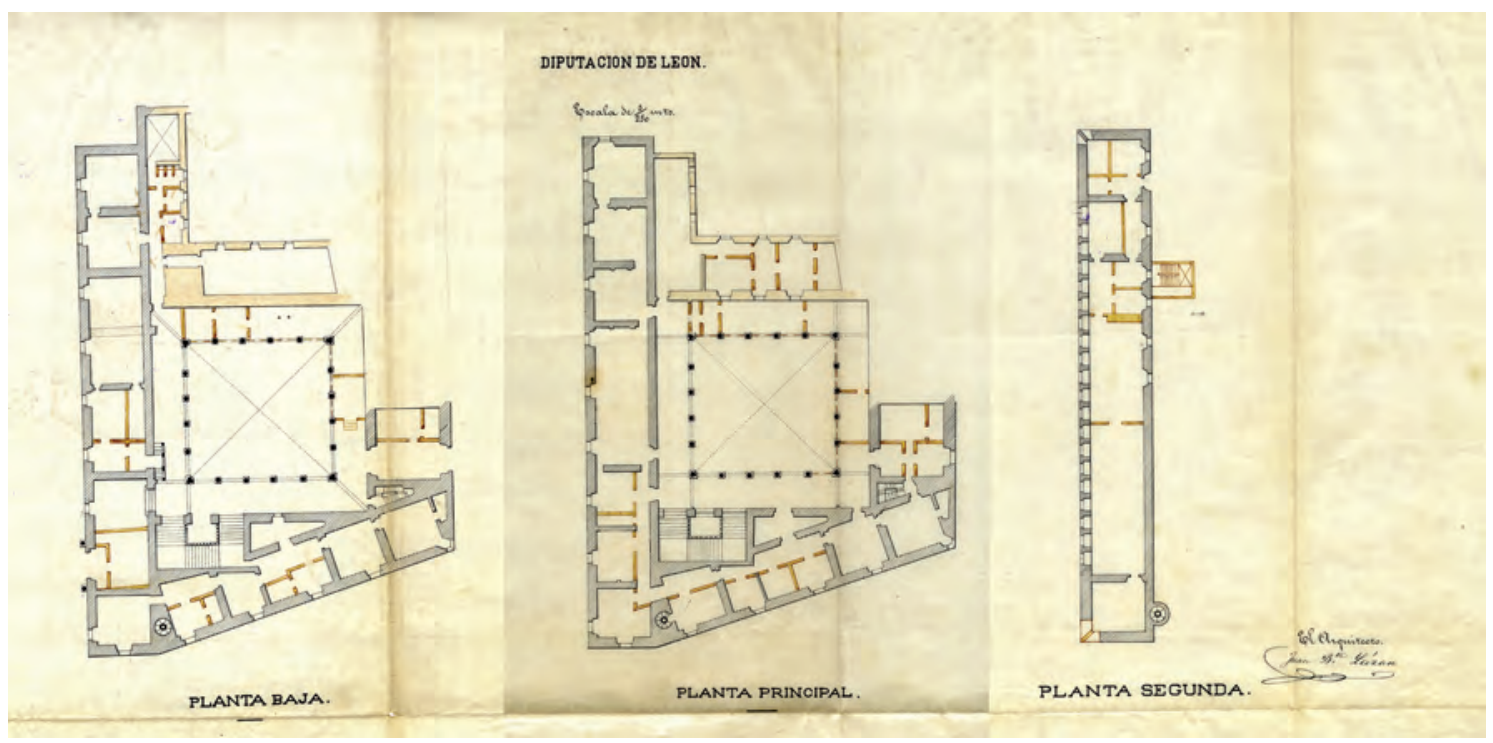

- Fig.11. J. B. LÁZARO DE DIEGO: Plantas de distribución del palacio de los Guzmanes antes de proponer Lázaro las obras de reparación necesarias (9 noviembre 1885) [Archivo Diputación de León. 20083/1. E.4-1]. 